\title{
Urban Elements in the Saudi Arabian Najd Region and their Influence on Creating Threshold Spaces
}

\author{
Mohammed Mashary Alnaim \\ University of Hail, Department of Architectural Engineering, Saudi Arabia \\ mm.alnaim@uoh.edu.sa
}

\begin{abstract}
Gathering spaces are a significant component of any type of built form. Many factors influence their shape, size, and location and how they are integrated with their surroundings. This paper investigates how urban elements generate gathering spaces, and how these generated spaces transform into threshold spaces within the built form. The aim is to understand how the urban elements played a role in shaping the urban spatial order. The Space Syntax analysis technique is used to examine and understand a number of factors related to space, territory, society, culture, and environment. The paper's objective is to discuss means of examining traditional architecture from the lens of cultural context. To reveal its concepts and embedded lessons developed by its society in the built heritage and use these key insights for problem-solving.
\end{abstract}

Keywords: urban culture, threshold, Najd, traditional architecture, space, socioculture, elements, placemaking

To cite this article:

Alnaim, M. M. (202I) Urban Elements in the Saudi Arabian Najd Region and their Influence on Creating Threshold Spaces, The Journal of Public Space, 6(I), 9-24. DOI 10.3289I/jps.v6il.I298

This article has been double blind peer reviewed and accepted for publication in The Journal of Public Space.

(c) $(5)$ This work is licensed under a Creative Commons Attribution - Non Commercial 4.0 International License https://creativecommons.org/licenses/by-nc/4.0/ 


\section{Introduction}

The main core concepts in each of the traditional Arab settlements are the "public urban elements" which are represented in the centre of most settlements. The centre of an Arab settlement and its urban elements - typically composed of a masjid al-jumaa (mosque for Friday prayers), a souq (market), and a barahaa (public space) emerge and combine to support the spiritual, economic, and social life of the settlement (Hakim, I986b; Abu-Ghazzeh, 1994).' However, from an organizational point of view, the center is considered to be a place that distributes the daily movement within the settlement and connects its parts by one binding urban space (Akbar, 1984; Al-Hathloul, 1985). In this sense, the public space and its elements are perceived as an integral destination within the spatial order in the traditional Arab built environment (Alnaim, 20I5). Therefore, in our study we chose five settlements distributed across $\mathrm{Najd}$, the central region of Saudi Arabia - old Riyadh, Alkhabra, Ad-Diriya, Ushaiqer, and Sudus - to examine the influence of urban elements on organizing the spatial order of the built environment. $^{2}$

Socio-cultural values, religious conventions, and daily life needs encouraged inhabitants to undertake the practice of their social lives in the public domain through the generation of gathering spaces (Jamalinezhada et al., 20I2). One of these spaces is the Al-Meshraq (which is a kind of bench made, allowing men to meet and sit outside at sunrise), another is the barahaa (open space), or inhabitants can simply meet by using the public symbolic elements as reference point for meeting and gathering (i.e., using the settlement's mosque minarets or main gates as references) (Eben Saleh, 1998; AlHathloul, 2010). This paper examines how the various urban elements in the traditional Arab settlements had the effect of creating physical or even virtual/perceived thresholds within the built environment's spatial order, serving to define and maintain the transition between the public and private domains (controlling points).

The traditional Arab built environment is characterized by its compact urban mass, which enabled its inhabitants to practice four core religious and social principles, Alshufa (neighbors' rights), ${ }^{3}$ Haq Alirtifaq (easement right), ${ }^{4}$ the principle of "no harm," ${ }^{5}$ and the preference for Alahyaa (reviving the land). ${ }^{6}$ In fact, these principles are the main mechanisms for the dual macro and micro decision-making processes which led to organize these four principles in a way that complement each other.

\footnotetext{
${ }^{\prime}$ All spaces are mixed gender usage except for the mosque which is only allowed for men.

${ }^{2}$ Case choices were driven by various considerations, such as availability of raw data, existing literature, whether the site can be visited for site observation, etc.

${ }^{3}$ Alshufa is an Islamic law which controls buying and selling. The Shufa principle, from this perspective, seeks to preserve the interest among different owners, ensuring that "no harm" others from one's actions. If multiple people are affected by this right, it is not permissible to sell to one person without selling to the rest.

${ }^{4}$ The "easement right" is the benefit of a property, such as drinking (from a well), traffic (street), land, etc., located within an owned personal property that the person does not own, but is owned by another person or owned by the entire local built environment. See more (Ar-Rami, 1995).

5 "No harm" is the principle that guides how people engage with each other on a daily basis. It establishes the mindset that one should exercise one's full right in what is rightfully his, provided that the decision/action will not generate harm to others (Hakim, 1986a).

${ }^{6}$ Reviving the land is based on the principle of freedom of action that Islamic law provides to individuals. Alahyaa as a principle of Islamic law of property whereby a person can acquire ownership of land from the State by way of rehabilitating or bringing back to life dead (mawat) land. See more (Ul-Haque, 1984).
}

I0 | The Journal of Public Space, 6(I), 202I | ISSN 2206-9658

City Space Architecture / UN-Habitat 


\section{The Process of Making Spaces}

Observing the built form's spatial order, including the location of main gates and secondary entrances, as well as the location of public urban elements, it is noticed that several thresholds were generated as mainly hidden boundaries or reference "control points," which defined the main transitional points in and increased the depth of the urban fabric's spatial order. These hidden boundaries or reference points work as socio-spatial regulators because people encoded them to refer to transitional zones that separate between two domains (Figure I).

Two representations were generally identified for how gathering spaces are placed within the built form: one, as a dual-function public space for gathering and acting as a threshold usually located on the borders between the public and semi-private domains and often integrated with a public building (i.e., a mosque); and two, as a threshold space located in the very deep private neighbourhood urban fabric (a hella). The threshold space here is usually used to define the border of semi-private and private spaces within the neighbourhood. The former relates to thresholds acting as the boundary space that separates two defined hellas, while the latter, a dual-functional space acting as a physical and nonphysical semi-public space that connect different parts of the built form and generates another layer of depth between the public and semiprivate domains.

The study noticed how the hella (urban mass/neighbourhood) is generated and organized, and how each hella is related to each adjacent hella by producing implicit boundaries defined by the inhabitants. The study's analysis of the settlements linked these implicit boundaries, for example, when examining how the local mosque functions as an explicit physical threshold between different hellas by its regular daily users (jama'at almasjed). ${ }^{7}$ The spatial order supported this process in the traditional Najdi settlements. Therefore, we argue that thresholds play significant roles in regulating outdoor activities and achieving culturally expected levels of privacy (Alnaim, 2020b). To understand how gathering spaces influence the built form's spatial order, the study divided the analysis of urban elements into four phases. The first phase is to observe, in general, the public urban elements, and their locations within the built environment by using the Space Syntax Axial Line connectivity map technique. ${ }^{8}$ The second phase is to generally identify the possible locations of thresholds within the five settlements after understanding the impact and location of urban elements. The third phase uses the Space Syntax Axial Line integration map technique to understand how these thresholds are an integral part of the settlement's spatial order. The fourth phase is a micro-level analysis to observe how gathering/threshold spaces can act as dual-functional spaces to integrate or separate between urban forms.

\footnotetext{
${ }^{7}$ A tightly related group of people who pray regularly in a particular mosque to gather in the Al-Meshraq (outside bench) after Fajer (early sunrise prayer) to practice their public social life.

${ }^{8}$ Space Syntax is a useful method for understanding a space or the hierarchy of a space. It can reveal the social meaning of the spatial system and the purpose of buildings (Hillier and Hanson, 1984; Hillier, 2005). The purpose of an axial map is to represent directions of uninterrupted movement and visibility. In an axial map, a set of lines intersect and cover an entire free space which then comprises a map of lines. See more (Hillier and Hanson, 1984; Jiang and Claramunt, 2002).
} 


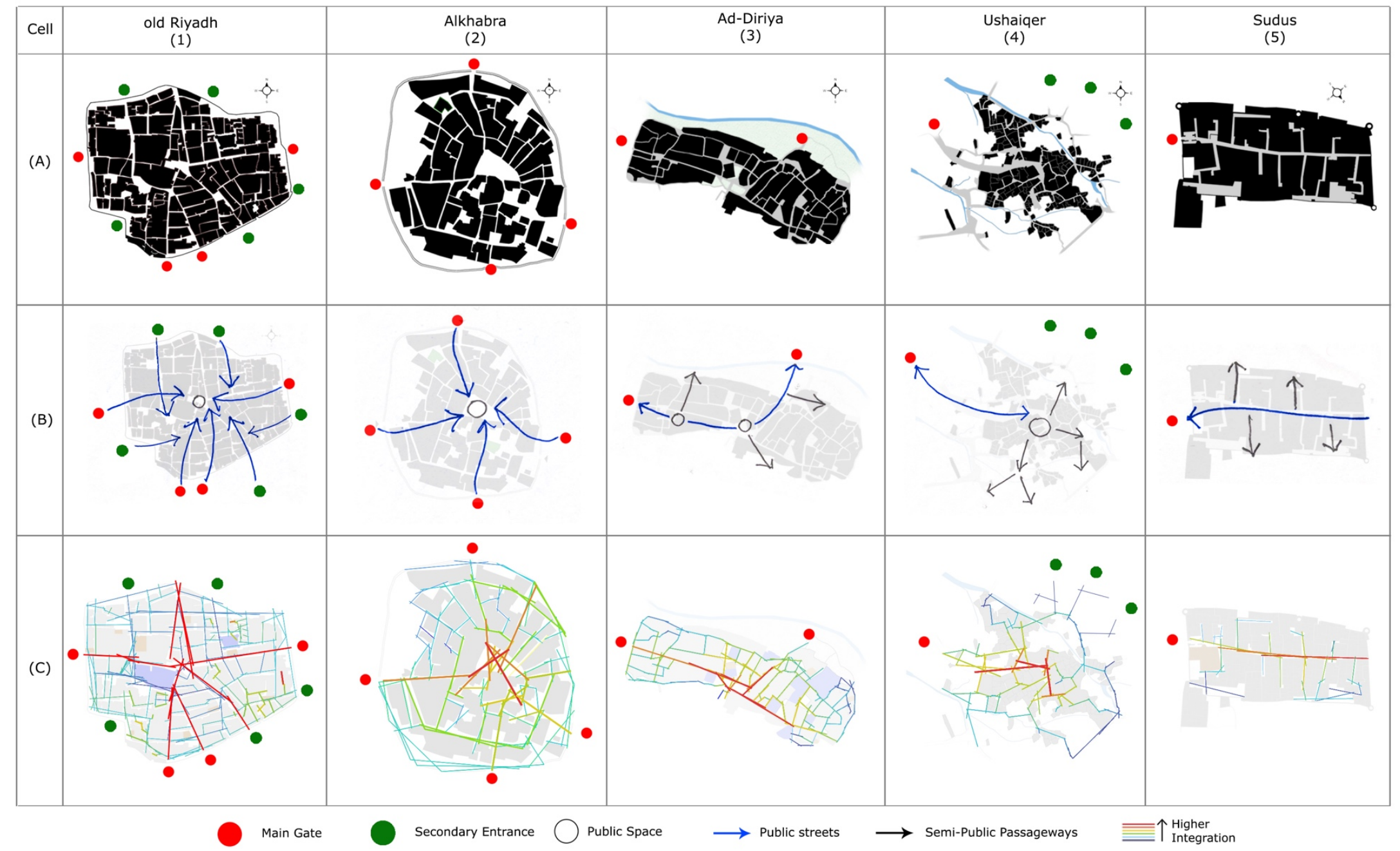

Figure I. (A) Shows the number of main gates in the selected traditional Najdi settlements, (B) How main gates and secondary entrances are linked with spatial order, and (C) The Space Syntax integration map analysis shows how the main gates and secondary entrances are integrated with the urban fabric. Source: Author. 


\section{Phase One: The Location of Public Urban Elements}

The different locations observed previously related to the public gathering spaces led to the in-depth analysis of how these spaces were located within the traditional built environment to support its inhabitants' daily life. In general, this study found that two types of mosques usually appear in traditional Najdi settlements near such spaces. In the first type, the mosque is large and placed on a public street. In the second type, the mosque is medium or small in size and is usually placed on a semi-public and semiprivate pathway. The fact that there are two mosque types, and the fact that they are placed within two different domains gives the indication that mosque location conveys the level of privacy of the location and can be a threshold in itself.

The two mosque types are generally identified by the mosque's location. Where the local mosque (i.e., the daily prayer mosque) is usually located inside or near the hella, the masjid al-jumaa (the Friday or grand mosque) is always located in the public domain and near the centre of the settlement. The size and location of a mosque has symbolic connotations and people usually use the mosque and its minaret as a visual reference to define the location (Figure 2) (ADA, 2015; Hessam, 2016).

One of the interesting customs related to the role of the mosque in the traditional urban order is that local people use the prayer time to invite people to meetings, while the time between prayers conveys the intended length of the meeting. ${ }^{9}$ For example, if the invitation is to meet after the Megreb prayer (the prayer at sunset), this means that the length of the meeting is likely to be very short because the Isha prayer (the night time prayer) is within one an hour of the start of the meeting. However, if the meeting is after the Isha prayer, it implies that the length of the meeting time is open because the next prayer, Fajer, (the sunrise prayer) is not until ten hours afterward. This makes the mosque location as a gathering space important to support the daily social life of the community.

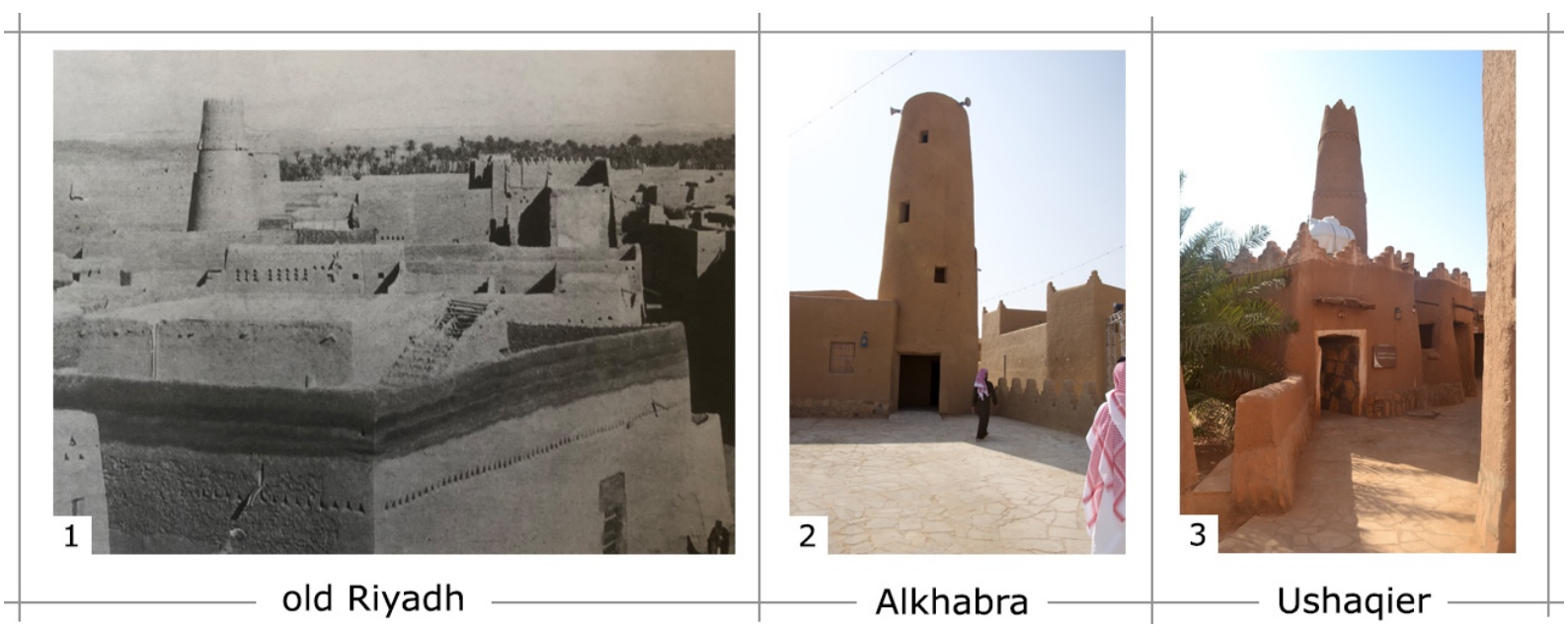

\footnotetext{
${ }^{9}$ Similar responses addressed in the interviews with local people in the five cases between 2016 and 2018. This leads to the conclusion that daily life is organized around the mosque and prayer time. This may explain how the mosque, as a physical element, is considered significant in the differentiation between the public and private domains.
} 


Settlements

Figure 2. The two mosques' types and their locations within the traditional urban fabric. Image Sources: (I) ADA, (2, 3) Author

\section{The Location of Public Urban Elements and their Relation to the Spatial Order}

To understand how the spatial order influenced the public urban elements of the traditional Najd settlements, the study examined the location of the two types of mosques and how each type is integrated with the public and private domains, according to the Space Syntax Axial Line connectivity map technique. The maps reveal that the jumaa mosque is usually placed in a public street (red) and is in close proximity with the souq square (market). The local mosques are located in semi-public and semi-private spaces (brown \& yellow) (Figure 3). We observed this phenomenon across the five cases except for Sudus, which is a small settlement and only has one mosque that serves one extended family. Connectivity map analysis demonstrates that the jumaa mosques are situated in higher connectivity streets, while the local mosques are located in less connected spaces in most of the chosen cases.

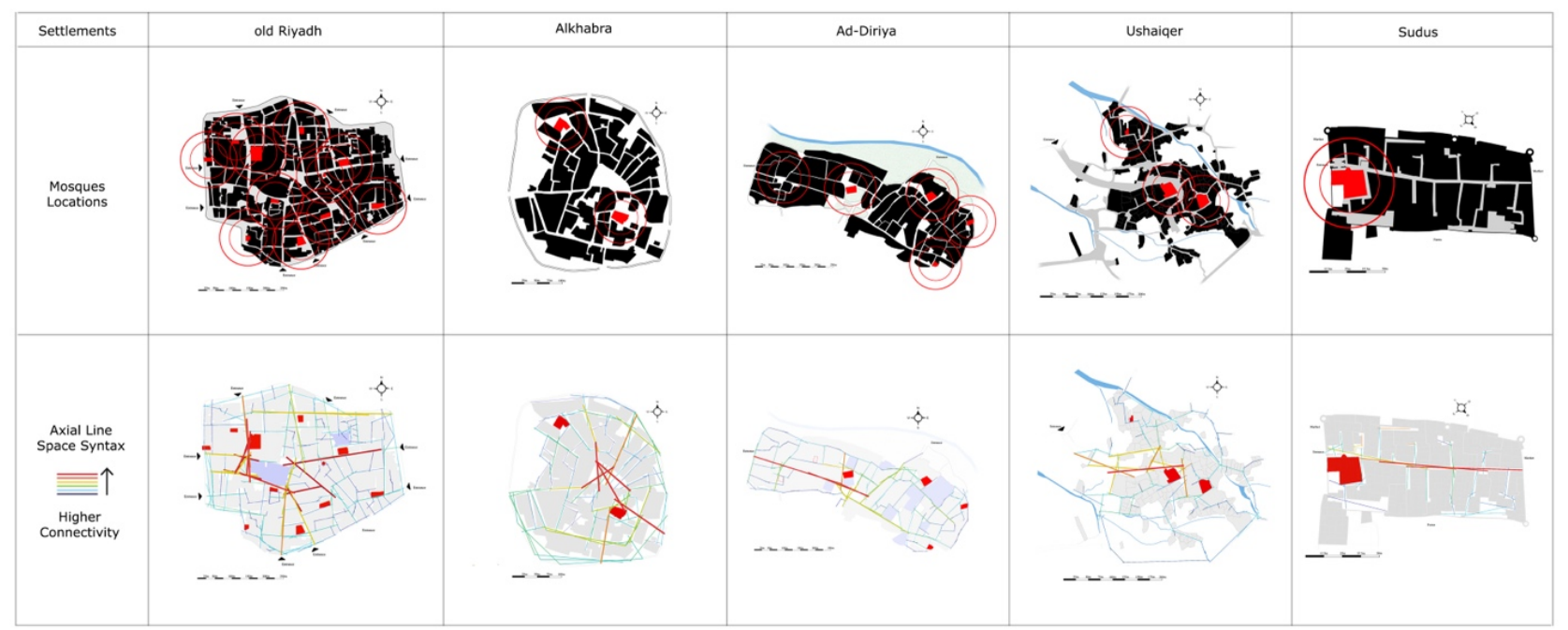

Figure 3. Mosque locations and their relation to the spatial order of the settlements. Source: Author.

Urban elements and their correlation to thresholds spaces within the built environment, we argue worked as a dual mechanism to supporting the community's inherited religious convictions, socio-cultural values, and its social structure, as well as acclimating inhabitants to the local climate and its harsh environmental conditions. The distribution 
of mosques within the urban fabric varies among the five cases, but in each case mosque placement serves to support the daily life and Friday prayers of each settlement. This is why several mosques were placed in different areas within the built environment to support social groups that are located within hellas, which makes the daily mosques within walking distance of the inhabitants.

Believers use the jumaa mosque for more than Friday prayer. It also functions as a place of daily prayer for the users of the souq (market) and its surrounding neighbourhoods. The jumaa mosque is associated with the central open space, which causes different people from inside and outside the settlement to use the mosque. In this sense, the souq square (market) and the jumaa mosque are linked, which makes many visitors from the surrounding settlements come to buy and sell goods in the market and pray in the mosque (Alearini, 20I0; Al-Ramali, 20I I). By grouping the jumaa mosque, the market, and the main open space in one communal area, the boundaries and the spatial limits are defined clearly for outsiders. This is a core concept and it is part of the wider group of common urban core concepts in the traditional Najdi settlements. The local people (men and women) in the region also understand this process as these urban core processes have existed in nearly every settlement, which makes them subconsciously decoded by strangers while visiting another settlement. ${ }^{10}$ In the local mosque (the daily prayer mosque), this mosque usually has a jama'at almasjed (a tightly related group of people who pray regularly in a particular mosque) to gather in the Al-Meshraq after Fajer (early sunrise prayer) to practice their public social life. In jama'at almasjed, the people usually identify users and the hidden urban boundaries (thresholds) of the hellas that are associated with the mosque. The spatial order where the main sekkak (pathways) lead to the jumaa mosque support these dynamic daily life needs. The size of the jumaa mosque building and the length of its minarets dominate the skyline of the whole settlement and lead everyone to the mosque, which leaves local mosques hidden and identified only by local people (Alnaim, 2020a).

It is important to mention that not all settlements have both jumaa and local mosques. For example, Sudus has only one mosque that combines the two types: jumaa Friday prayer and daily prayer. This is because it was a small settlement composed of seventy houses, and the walking distance to the one mosque was acceptable for all the residents. The difference in use here did not affect the generative process of the spatial order among the five cases, but it is possible to say that the Sudus' inhabitants exhibited a similar interpretation of the process of producing the built environment, which resulted in a different outcome based on the different circumstances of Sudus. In fact, Sudus is representative of how the Najdi settlements emerged. Although it was the oldest selected settlement, it remained without expansion. As discussed throughout this paper, the Najdi traditional settlements followed a common pattern of limitation in their urban development that was based on the demographic size of each settlement. If the settlement exceeded the limit of its resources, usually a group of families would move and create a new settlement."

\footnotetext{
${ }^{10}$ Based on a number of focused groups interviews in Old Riyadh, Alkhabra, Ushaiqer, Saudi Arabia between 2017-2018.

"A socio-urban phenomenon called "Alkhoboub" which is typically when an area is occupied by one or more families who separated from the earlier larger towns and moved to generate a new one. This is an
} 
Even though the public urban elements contain a souq square and a barahaa central open space, it seems that the two types of mosques are more significant in influencing and defining the public and private domains. This is because the souq and the barahaa are only seen in the centre and identified by the majority as public urban elements, while the mosques are distributed in the public and private domains and are associated with urban socializing elements that are mainly used by the inhabitants. ${ }^{2}$

Examining the mosque location within the built environment led us to assume that a number of spaces (thresholds) are formed near the mosque. These spaces, we argue, are dual-function and are usually used as gathering spaces in the daytime and at prayer time to integrate as many neighbours in one place as possible. At night, the same space can be used as a space that defines the boundary between a number of private spaces; To be the space that separates or defines the limits of adjacent private domain.

\section{Phase Two: The Location of the Threshold Space}

So far in this paper, the public, semi-public, semi-private, and private spaces ${ }^{13}$ identify the organization of the spatial order in the traditional Najdi settlements. These different spaces are essential for defining the boundaries of different domains. These boundaries can take many shapes, such as the different street shapes and forms, the architectural element of Mujabab, ${ }^{14}$ and the location of a local mosque. However, in most cases, the threshold is mainly nonphysical and mostly hidden, decoded and deeply rooted in the subconscious of the local people. This generative mechanism for how local people engaged with the placemaking process enabled them to use the spaces in a way that didn't interfere with the cultural settings. We argue that the threshold is part of this process and local people generated it to define their private boundaries and separate them from the interventions of the public activities.

We found that the existence of thresholds contributed to increase the organization of the urban fabric in two ways. First, thresholds created another layer of depth between the different domains, and second, they defined the limitations of street types that provided a link between the different domains. These two ways in which the organization of the urban fabric was produced helped to achieve several purposes including creating a gradual depth between spaces, distributing the density of the spatial order, influencing the pattern of streets, and identifying the location of semi-public, and semi-private spaces (Figure 4). In the following phase, the location of the threshold is examined in more in-depth to understand the different uses of such a reference point.

\footnotetext{
observation related to a focus group interviews in Alkhabra, Saudi Arabia on I/I/20I8 and in Ushaiqer on 12/28/2017.

${ }^{12}$ From a religious point of view, it is preferable to have one mosque for jumaa (Friday) prayer in each settlement and an unlimited number of local mosques for daily prayer. The purpose of having one Friday mosque is to bring all the residents of the settlement to one place at least once a week, as well as to protect the spatial order of the settlement and sustain the privacy of its private domains. See more (AlZubaidi 2007; Alzahrani, and Eisa, 2007; Alajmi, 2010).

${ }^{13}$ They form the area or place that is open, accessible to all peoples, and connect different zones within the built form, regardless of gender, race, ethnicity, age, or socio-economic level. That is why it is argued that this space may form kind of spatial organization.

${ }^{14}$ A Mujabab (pl. Mujabibat) is a bridge room architectural element between two houses, often seen above the street.
} 
The objective is to identify how the concept of the threshold is an integral part of the built form's spatial order.

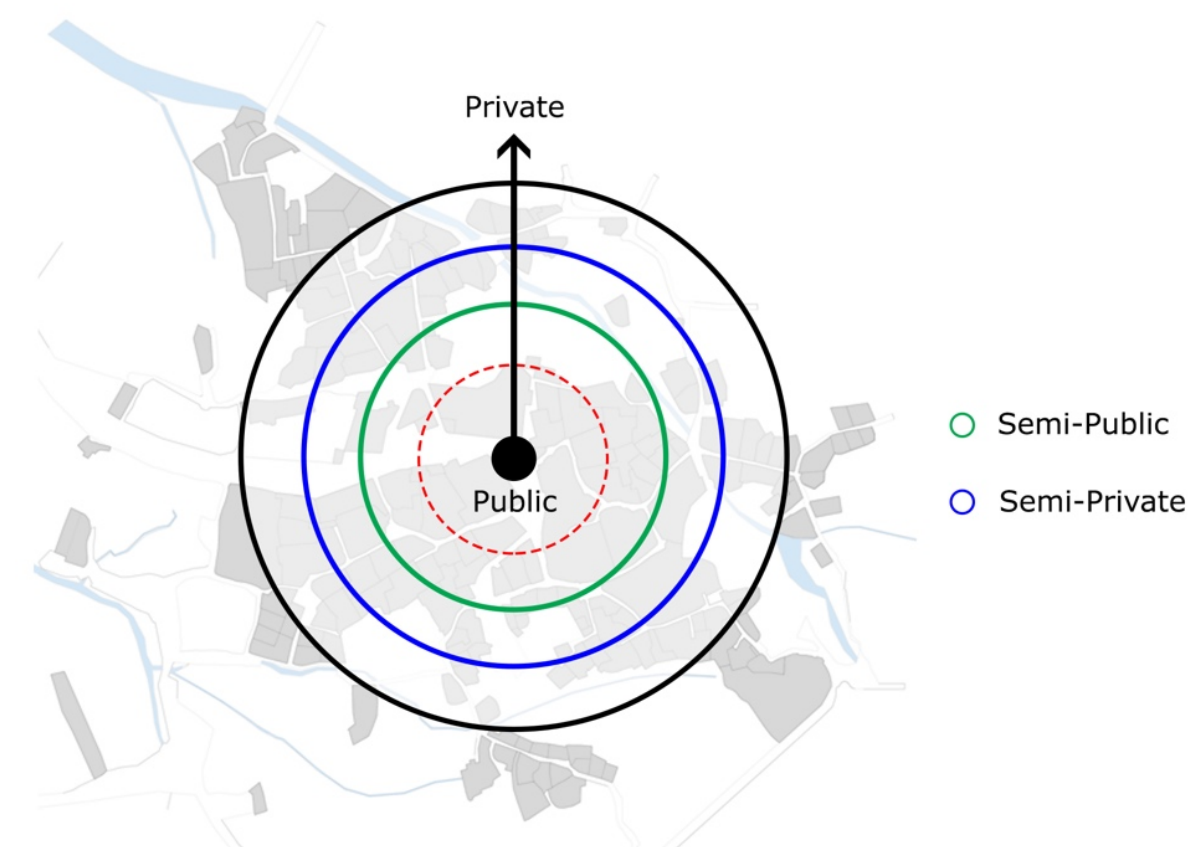

Figure 4. Threshold gradual depth in the traditional Najdi settlements. Ushaiqer settlement. Source: Author.

\section{Phase Three: Thresholds as a Space of Integration and Separation}

By using the Space Syntax Axial Line integration map technique, the way in which thresholds are located is examined as well as identifying the domain to which each threshold belongs (Figure 7: B). Typically, the maps show that thresholds are found in the semi-public or in semi-private spaces. The semi-public streets that have high to medium traffic generated threshold references to mediate the density of the street (red or brown) (Figure 7: BI, 2 \& 4), while in semi-private pathways that have lower density traffic, the threshold spaces were located to define the boundaries between the housing clusters within the neighbourhood (yellow or green) (Figure 7: B3 \& 5). The fact that thresholds are located at these two types of spaces supports this study's argument that the threshold reinforces the gradual transition of spaces that either integrates or separates the public and private domains (see Alnaim, 2020b).

This paper sees the concept of threshold as a social concept which sometimes has a physical representation. Amos Rapoport argues that place and space could contain symbolic connotations, cognitive/cultural space, or social space, each of which can embody different meanings associated with how people made use of these places and spaces (Rapoport, 1977). Rapoport's argument is related to what is meant by thresholds as integration and separation spaces as Rapoport posits that a threshold has a hidden meaning in that it can become a meaningful concept only when the inhabitants understand the particular use of it (Also see Sait, and Lim, 2006). This makes the concept of thresholds depend on how people experience and perceive the space (Figure 5). 


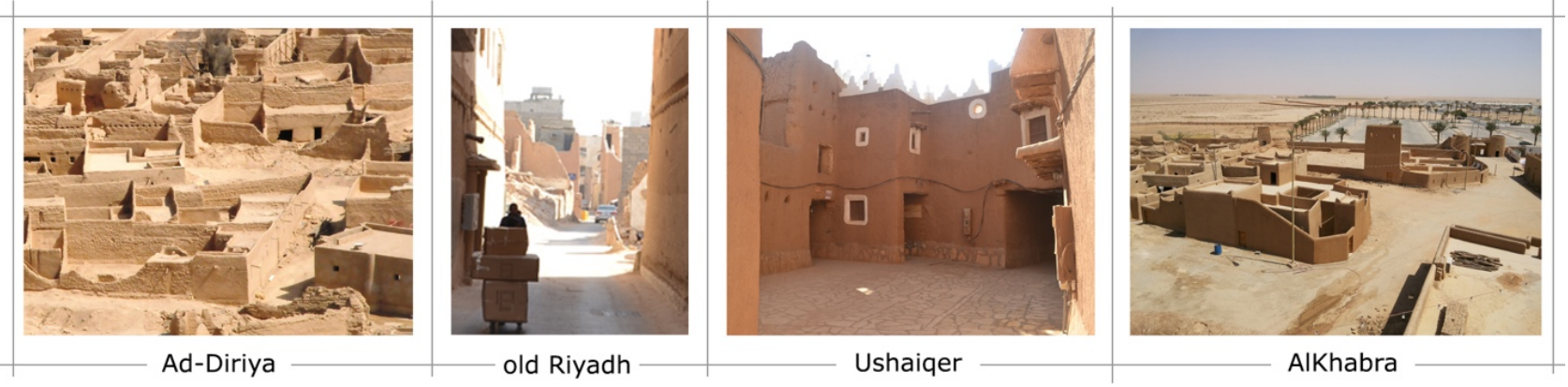

Figure 5. Different formations of the threshold space. Source: Ad-Diriya by ADA, Author.

To support this argument, we made use of the results of an interview with a Saudi professor conducted in 2017. ${ }^{15}$ The interview discussion focused on the importance of open spaces in the traditional built environment. From the professor's childhood experience, as he lived in one of the Najdi traditional settlements, he recalls that he usually played in an open space placed between two hellas nearby his family's house. As a child, he considered the surrounding space as his limit in interacting with the external domain. He mentioned that the importance of this space was significant to him, as it brought he and his friend from a different hella into one space. The open space was accessible to him and other young neighbours all day due to the supervision of wellknown neighbours who knew him and his family and the other young people and their families. In fact, thresholds that separated the common playing spaces from the family private spaces defined his play space well.

For him, the playing space was a semi-private space that protected him from outer and larger public spaces by having another threshold (in semi-public) that defined the boundaries of spaces he should occupy. However, the same space was also a threshold space that integrated two hellas which means that one can encounter some thresholds from different perspectives. One perspective is the definition of the internal spaces within one domain while the other perspective is the definition of the separation or integration points between different domains. The importance of the shared meanings is to maintain the cultural settings while individuals can establish a meaning for themselves and shared with their own families without disturbing the shared one. This means that the concept of a threshold is both physical and nonphysical which makes it a dynamic mechanism that gave the inhabitants the ability to generate references to enable them to define their spaces individually (among the family members) and collectively (across the entire community).

A developed schematic graph shows how the thresholds serve as a concept that simultaneously integrates or separates public and private spaces. Two key concepts simplify the complexity of the concept:

First, the threshold is usually considered a semi-public space that separates public and semi-private spaces (Figure 6: A). This threshold appears when the semi-private spaces or private hellas are nearby the souq square (market). The purpose here is to create a layer of depth that gradually separates the most private spaces from the most public

\footnotetext{
${ }^{15}$ We asked if we can provide his name and he preferred to make it anonymous as it was a conversation related to his own personal life. An interview in his private home in Riyadh 1/9/2017
}

I 8 | The Journal of Public Space, 6(I), 202I | ISSN 2206-9658

City Space Architecture / UN-Habitat 
spaces. This process generates a semi-public threshold. We observed the threshold across the five cases, but it is most apparent in old Riyadh, Alkhabra, and Ushaiqer. Second, the threshold is usually located in semi-private spaces and acts as a hidden boundary to separate two hellas (Figure 6: B). This threshold space appears between two hellas in the semi-private domain to define the boundaries of each urban mass. It is in this threshold that semi-private open spaces or local mosques are observed most often. The importance of this threshold is that it has dual transitional meanings, either integrating or separating two different hellas. These generated meanings depend on the social activities of the two hellas and level of interaction between the hellas. While we observed this threshold across the five cases, it is most apparent in Ad-Diriya, Ushaiqer and Sudus.
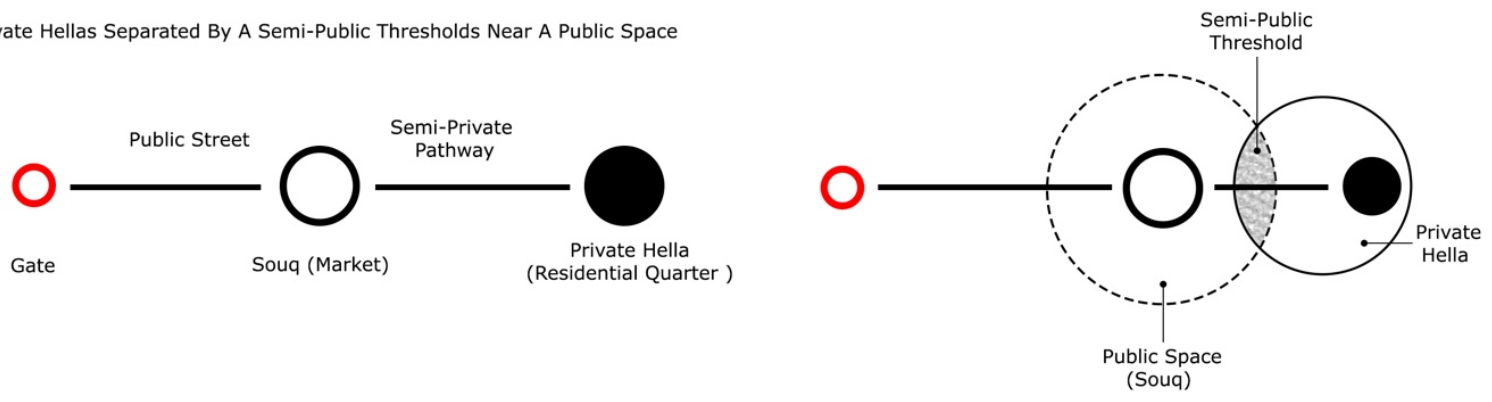

(B) Two Private Hellas Separated By A Semi-private Threshold
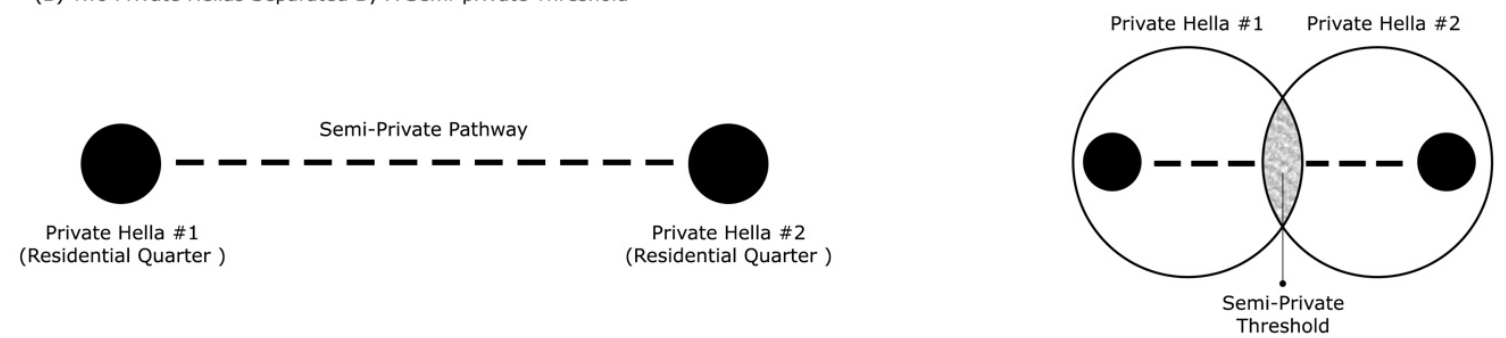

Figure 6. A schematic representation to examine the functions of a threshold Source: Author 


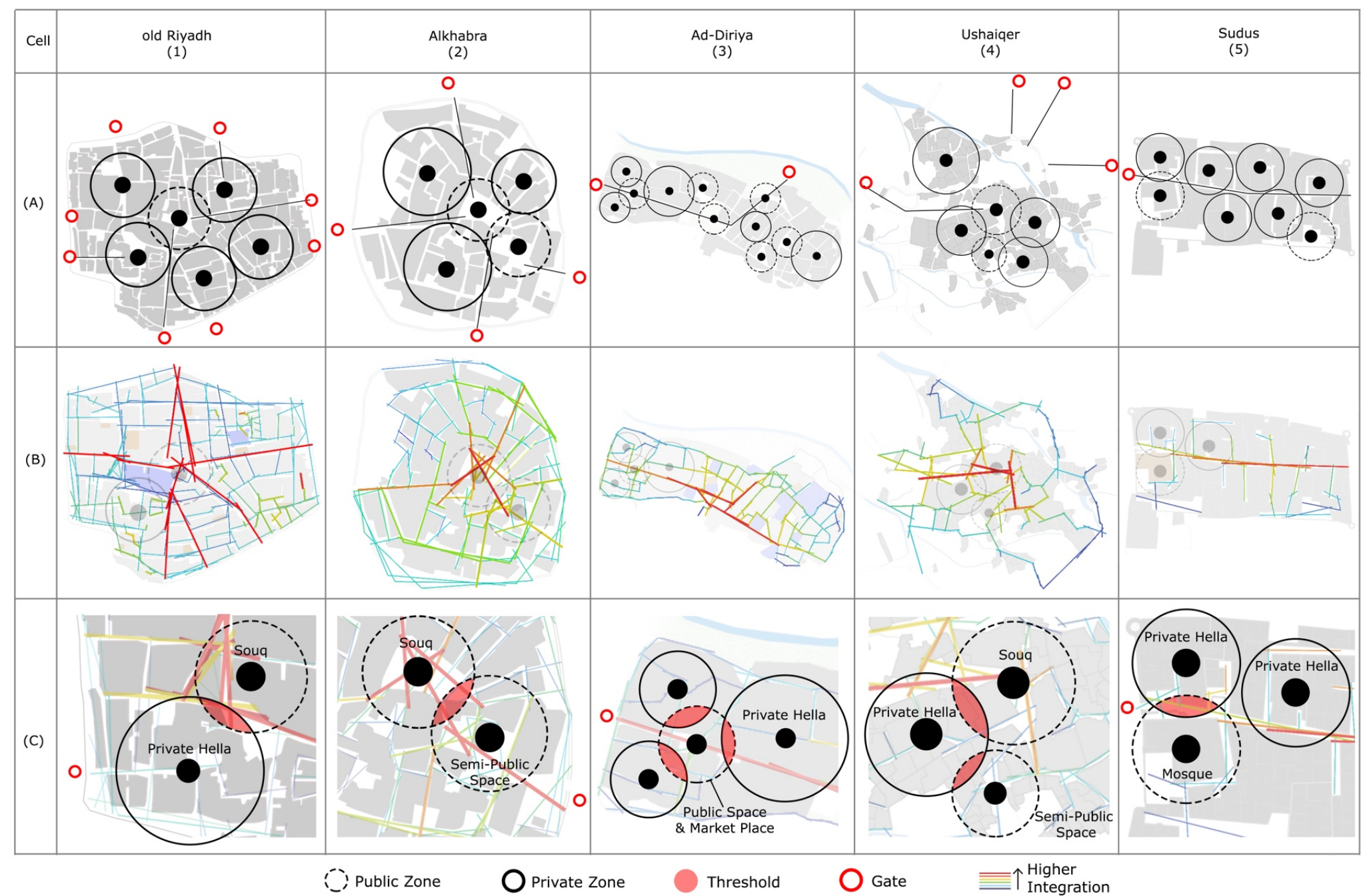

Figure 7. Examining the threshold level using the Space Syntax Integration Maps method to examine the distribution of thresholds in the traditional Najdi built environment. Source: Author. 


\section{Phase Four: The Implicit Meanings of The Threshold Space}

The locations of thresholds and their possible associated meanings in the traditional Najdi settlements were examined, and it was found that a threshold is either a physical or a nonphysical reference point that is located in one of two positions. The first position is at the edge of two different domains, serving to separate them by defining the border between them. The second position is within a particular domain, integrating or separating two urban masses (Figure 7). The spatial order, the location of the settlement's main gates and secondary entrances, and the central public urban elements determined which type of buildings and activities were placed in particular spaces. This means that the organization of the urban spatial order encourages circulation on public streets, which enables the semi-private and private cul-de-sacs to appreciate lower traffic levels. In this connection, the placement of the threshold is between the higher and lower traffic streets to mediate the direct link between the public and private streets. In this sense, the threshold location here is intended to enable the private domain to engage with its private spaces while the public spaces are occupied (Figure 7: A).

In the case that the thresholds are located inside the private domains, these spaces are usually located between two hellas, and either a local mosque or small semi-private open space serves to define these thresholds. The threshold, in this case, is acting as an implicit boundary that local people identify and decode. The boundary here is presented physically as open space or a local mosque that is shared between two hellas, but most importantly, its nonphysical meaning indicates the permitted and unpermitted areas that people can use or enter. This is important as not all thresholds in the settlements are presented physically as they can be a regular semi-private pathway between two hellas. This semi-private pathway is acting as a nonphysical threshold that embodies meanings that function to either integrate or separate the space between the adjacent hellas. In fact, the concept of threshold, then, is not necessarily well-defined open space which makes the implicit meanings that the inhabitants share and agree upon more significant in establishing those reference points within the built environment. In general, the spatial order and the carful placement of urban elements supported the concept of the threshold. A threshold functions to control the limits and define the borders of different spaces, while maintaining respect for the social structure, and creating another layer of depth in the spatial order. The threshold is a space that integrates different spaces controlled by different domains to increase the homogeneity of the urban fabric or function as a space that increases the separation between the public and private domains. Also, the threshold can have physical or nonphysical references that define the end of one space and the beginning of another. This diversity in the shape and nature of thresholds indicates how this device was used widely as a regulator and organizer of spaces and architectural components in the traditional Najdi built environment.

\section{Conclusion}

Examining various processes of interpretation related to the urban elements helped to identify several processes with different embedded meanings that directly influenced the traditional Najdi built environment's spatial organization. These elements followed a specific process in generating forms and spaces while having some flexibility in integrating with the urban form. This was possible as the two levels of the decision- 
making process - the macro and micro levels - increased the possibility for the Najdi local community to be involved in the concept of placemaking. This is because at the macro-level, the impact was minimal, and inhabitants made most of the decisions that shaped the traditional Najdi built environment and maintained its existence within the shared and agreed upon spatial order at the micro-level. This, in fact, produced a very similar, but not identical process of generating spaces and forms across the five cases, which led the inhabitants to produce elements that implicitly communicates, where the communication reflects and influences the organization of space and meaning. Place, which constitutes a space, is a social production and any neglect of human practice will affect the tracing of spatial representations, spatial practices, and the physical representation of spaces. Gathering places and public spaces in the Arab world must be redefined and must be more aligned with socio-cultural priorities and values. Lessons presented in this study showcased how the mosque can be both a place of reference as well as a space that accommodates religious and social rituals. That said, one of the main challenges in the contemporary built environment is to reengage people's participation (especially participation of children, youth and women) in the decision-making process and enable them to reflect their collective interests in their living spaces. The dual relationship between the location of urban elements and gathering spaces can help the people to reproduce/infuse their socio-cultural values and priorities into their shared built environment while also responding harmonizing with their surrounding natural environment.

What is clearly noted in this paper is that the physical elements and spaces of a community must integrate with should parallel with people's needs values and beliefs. The scale of the contemporary built environment and the diversity of its people's values, interests, and visions, as well as the vast advancement in building technology are drastically different from those of the traditional Najd settlements. However, the opportunity exists to learn from the past, infusing modern communities with similar abilities to clarify the use and perception of space from public to semi-public, to semiprivate, and private, through the use of thresholds, thereby increasing the quality of space and quality of life enjoyed by contemporary communities.

\section{Acknowledgements}

The authors would like to thank Saudi Arabia governmental entities, and all other individuals for their support and their sharing of data, which improved the quality of the survey output.

\section{References}

Akbar, J. (1984). Responsibility and The Traditional Muslim Built Environment. Unpublished PhD thesis, USA: Massachusetts Institute of Technology.

Al-Hathloul, S., \& Anis, R. (1985). The Evolution of Urban and Regional Planning in Saudi Arabia. Ekistics, 52 (3I2), pp. 206-2I2.

Al-Hathloul, S. (1996). The Arab-Muslim city: Tradition, Continuity and Change in The Physical Environment. Riyadh: Dar Al Sahan.

Ar-Rami, Ibn. (XV Century) (1995). Al-llan bi Ahkam al-Buniyan ed. Al-Atram S. Riyadh: DarIshbiliya, (Arabic). 
Abu-Ghazzeh, T. (1994). 'Built Form and Religion: Underlying Structures of Jeddah AlQademah.' International Association for the Study of Traditional Environments, Traditional Dwellings and Settlements Review, 5 (2), pp. 49- 59.

Al-Zubaidi, M. (2007). The Sustainability Potential of Traditional Architecture in the Arab World- With Reference to Domestic Buildings in the UAE. Unpublished PhD thesis, England: University of Huddersfield.

Alzahrani, S., \& Eisa, J. (2007). 'Traditional urban patterns in Assir region.' Damascus University Journal, I, PP. 189-228.

Alajmi, M. (2009). History of Architecture in Kuwait: The Evolution of Kuwaiti Traditional Architecture Prior to the Discovery of Oil. Unpublished PhD Thesis, USA: University of Nebraska.

Alearini, A. (2010). 'Alkhabra old and New.' AlJazeera News Paper, Retrieved from http://www.aljazirah.com/2010/20100627/wo3.htm, (Accessed on July 18, 2019) (Arabic).

Al-Ramali, F. (20II). 'The Tourism of Alkhabra.' Middle East News Paper, No. I 1973, Retrieved from Archive.aawsat.com (Accessed on July 18, 2019) (Arabic).

Arriyadh Development Authority (ADA). (2015) Riyadh: History, tradition and Vision. Riyadh: ADA, (Arabic).

Alnaim, M. (20I5). Al-Fereej: Rituals and Ceremonies of the Traditional House in Alhasa, Saudi Arabia. Saudi Arabia: Al-Turath (Arabic).

Alnaim, M.M. (2020a) 'The Hierarchical Order of Spaces in Arab Traditional Towns: The Case of Najd, Saudi Arabia.' World Journal of Engineering and Technology, 8, pp. 347-366.

Alnaim, M.M. (2020b). 'The Concept of Access and the Mechanisms of the Threshold Space in Arab Traditional Built Environment: The Case of Najd, Saudi Arabia.' Global Journal of Science Frontier Research: A Physics and Space Science, 20(9), PP. I-I8. 
Eben Saleh, M. (1998). 'The Impact of Islamic and Customary Laws on Urban form Development in Southwestern Saudi Arabia.' Habitat International, Elsevier Science Ltd., 22 (4), pp. 537-556

Hillier, B. \& Hanson, J. (1984). The Social Logic of Space. London: Cambridge University Press Hillier, B. (2005). 'The Art of Place and the Science of Place.' World Architecture, I85, pp. 96102.

Hakim, B. (1986a). Arabic-Islamic Cities: Building and Planning Principles. London: Kegan Paul International.

Hakim, B. (1986b). 'The "Urf' and its Role in Diversifying the Architecture of Traditional Islamic Cities.' Journal of Architectural and Planning Research, Pp. 108-I 26.

Hessam, K. G. (2016). 'Evaluation of the Relationship Between Culture and Traditional Architecture and its Effects on Design Quality Improvement.' International Journal of Applied Engineering Research, I I(3), pp. 2I20-2I 23.

Jiang, B., \& Claramunt, C. (2002). 'Integration of Space Syntax into GIS: New Perspectives for Urban Morphology.' Transactions in GIS, pP. 295-309.

Jamalinezhada, M., Seyed, T., \& Soltanic, S. (2012). Islamic Principles and Culture Applied to Improve Life Quality in Islamic Cities. Procedia - Social and Behavioral Sciences, 35, pp. 330-334.

Rapoport, A. (1977). Human Aspect of Urban Form: Towards a Man Environment. Oxford: Pergamon Press.

Sait, S., \& Lim, H. (2006). Land, Law, and Islam: Property and Human Rights in the Muslim World. London: Zed Books Ltd.

Ul-Haq, S. (1992). Meaning in Architecture: An Investigation of the Indigenous Environment in Bangladesh. Unpublished PhD Thesis, USA: Massachusetts Institute of Technology. 